\title{
De los duelos clandestinos a las búsquedas de desaparecidos.
}

(Experiencias de buisqueda de combatientes de las FARC en el escenario del postacuerdo de paz en Colombia)

$$
\approx
$$

From Clandestine Duels to Searches for the Disappeared. (Experiences of Searching for FARC Combatants in the Scene of the Post-peace Agreement in Colombia)

\section{Lorena Carrillo González*}

Universidad Nacional de Colombia

Colombia

Correo: scarrillog@unal.edu.co

https://orcid.org/0000-0002-9575-98I5

DOI: 10.48I02/hyg.vi56.356

Artículo recibido: 6/07/2020

Artículo aceptado: 4/09/2020

* Una versión inicial de este escrito fue realizada en el año 2018, a raíz de la experiencia de la autora como secretaria técnica del comité de acompańamiento de la sociedad civil al Mecanismo de Monitoreo y Verificación del Cese al Fuego y la Dejación de Armas, tiempo en el que conoció varias experiencias y personas que aportaron sus voces para la construcción de este texto. Aunque la autora es funcionaria de la Unidad de Búsqueda de Personas dadas por Desaparecidas de Colombia, este artículo expresa sólo sus opiniones personales y da cuenta de su trayectoria como investigadora. Se aclara que para su construcción no se utilizó ninguna información recabada a través del trabajo en la entidad, que guarda reserva y es de carácter confidencial. 
ABSTRACT

This article takes up experiences of the search for missing and disappeared FARC combatants, carried out by relatives and ex-combatants. I aim to explain how the lives of thousands of 'guerrilleros' killed during hostilities were never considered as liveable lives by different State entities and the majority of Colombian society. This situation has determined how relatives of fallen combatants have had to carry out searches and duels clandestinely, without bodies or certainties. My purpose is to point out that the impossibility of valuing those lives, by giving them names and recognizing their stories has profound implications for attempts to build community in Colombia. Especially, having in mind the current post-agreement scenario, which is still living the armed conflict.

Key words: FARC, Search, Missing Persons, Clandestine Duels, Colombia, Peace Agreement.

\section{Resumen}

El presente artículo retoma algunas experiencias de búsquedas de combatientes de las FARC dados por desaparecidos, emprendidas por familiares y excombatientes, para exponer cómo las vidas de los miles de guerrilleros, muertos durante las hostilidades, no fueron consideradas como vidas vivibles por parte de distintas entidades estatales y del grueso de la sociedad colombiana. Ello determinó las formas en las que familiares de combatientes caídos en combates, u otras operaciones militares, han tenido que hacer las búsquedas y los duelos: de forma clandestina, sin cuerpos, sin certezas. Señalo con ello que la imposibilidad de valorar esas vidas, de darles nombres y reconocer sus historias, tiene implicaciones profundas en los intentos de construir comunidad en un país como Colombia, en el actual escenario de postacuerdo, que sigue atravesado por el conflicto armado.

Palabras clave: FARC, desaparecidos, búsqueda, duelos clandestinos, Colombia, Acuerdo de Paz. 
A MODO DE INTRODUCCIÓN:

HISTORIA DE UN CUERPO EN TRES VIÑETAS

Como si por el hecho de haber estado allá [en la guerrilla] uno no sintiera, ni tuviera sus pérdidas, y eso deja muchos vacíos en uno.

Emilia, excombatiente de FARC ${ }^{1}$

1) Fue el 23 de septiembre de 2010. En desarrollo de la
Operación Sodoma, las fuerzas militares colombianas dieron uno de los golpes más certeros a la antigua guerrilla de las FARC-EP: el bombardeo contra uno de sus máximos comandantes, Víctor Julio Suárez, mejor conocido como Jorge Briceño o el famoso Mono Jojoy. Las acciones militares de Briceño acapararon numerosas notas en los medios de comunicación durante largos años en Colombia, fue señalado de ser uno de los hombres más violentos de las Farc. Su muerte fue celebrada por el entonces presidente Juan Manuel Santos: "El símbolo del terror en Colombia ha caído en una operación que realizaron las Fuerzas Armadas. Alias Mono Jojoy fue dado de baja, eso es una noticia histórica. Es el golpe más contundente que se ha dado a las FARC en su historia". ${ }^{2}$ El entonces ministro del Interior, Germán Vargas Lleras, elogió a las fuerzas militares: "Esta es una gran noticia, ya que por muchos años 'El Mono Jojoy' cometió innumerables atrocidades en este país [...] aprovecho para felicitar a la Fuerza Pública, al Ejército, por la forma en que organizaron de manera tan detallada el operativo". ${ }^{3}$ Las fotografías del cuerpo de Briceño fueron pu-

\footnotetext{
${ }^{1}$ Nombre cambiado a solicitud de la persona entrevistada. Entrevista realizada en junio de 2020.

2 "Muere en un bombardeo el jefe más sanguinario de las FARC". Disponible en: $<$ https://elpais.com/internacional/2010/09/23/actualidad/1285192803_850215. html>. Consultado el 9 de junio de 2020.

3 “Declaraciones por la muerte del Mono Jojoy". Disponible en: $<$ https://www. elcolombiano.com/historico/declaraciones_por_la_muerte_del_mono_jojoy-AEEC_105335>. Consultado el 9 de junio de 2020.
}

De los duelos clandestinos a las búsquedas de desaparecidos / 197 
blicadas en varios medios de comunicación, advirtiendo que eran "fuertes" y que se tenían que ver "bajo responsabilidad" del lector.

2) Pasaron dos meses y el cuerpo de Víctor Julio Suárez no había sido entregado aún a sus familiares (jlos tenía!). Para reclamarlo, su sobrina y hermano tuvieron que dirigirse desde su natal pueblo, Cabrera, ubicado en el departamento de Cundinamarca a un par de horas de Bogotá, a la sede del Instituto Nacional de Medicina Legal y Ciencias Forenses, a fin de que les fueran tomadas muestras para cotejar el ADN. Pese a que las pruebas demostraban el parentesco, la entrega del cuerpo pasó a ser un asunto judicial de seguridad nacional. En sus viajes al Instituto, rompiendo su anonimato, los familiares de Jorge Briceño sufrieron agresiones y señalamientos:

Lucero Hipus, sobrina de Jojoy y Aníbal Peralta Rojas, hermano del líder subversivo han sido retratados por la prensa y burlados en la calle por quienes los señalan de ser familiares de uno de los hombres más sanguinarios de las FARC. Tanto que ahora piensan antes de salir a la calle y desde su humilde residencia hablan con la gente detrás de una ventana. ${ }^{4}$

La Fiscalía General de la Nación señaló en ese momento que el cuerpo debía ser enterrado en un cementerio de la capital del país, y no en su pueblo natal — como lo querían sus familiares_ " cuestiones de seguridad". Tras un proceso en el juzgado, que finalizó en diciembre de 2010, se condicionó la entrega del cadáver a su familia a que, de acuerdo con las indicaciones de la Fiscalía, éste fuera sepultado en Bogotá: "La juez alega que si el cuerpo de Suárez Rojas, abatido a fines de septiembre, es sepultado en su pueblo natal de Cabrera, ubicado a 80 kilómetros al sur de la

4 "La familia del Mono Jojoy reclama su cuerpo". Disponible en: <https:/www. elmundo.es/america/2010/10/15/colombia/1287175169.html>. Consultado el 10 de junio de 2020 . 
capital, hay riesgos de que la guerrilla lo desentierre y se lo robe". 5

3) Siete años después de su muerte, en septiembre de 2017, un grupo de militantes del ahora partido político Fuerza Alternativa Revolucionaria del Común, FARC, entre los que se encontraba Chepe, hijo del Mono Jojoy, tramitaron su reubicación dentro del mismo cementerio El Apogeo, al sur de la capital. Llevaron rosas, una placa y se reunieron para poder hacerle "una despedida digna”. La antigua tumba de Jorge Briceño era poco visitada:

El contraste era chocante y el color sobresalía entre las lápidas blancas y sus leyendas despintadas. Y es que, al Mono Jojoy, según se dice, no lo visitaban ni las sombras. Pero el olvido en el que cayó después de la Operación Sodoma, se empezó a transformar con un desfile de anónimos que salieron de la clandestinidad para rendirle honores en el sur de Bogotá. ${ }^{6}$

¿Por qué las autoridades judiciales terminaron decidiendo cómo debía disponerse del cuerpo? ¿Deben los órganos judiciales condicionar las formas de hacer un duelo? ¿Un entierro se puede convertir en un asunto de seguridad nacional? ¿Por qué importaría a la Fiscalía colombiana si el cuerpo de Jorge Briceño hubiese sido "robado"?

Uno de los efectos - menos visibles - del Acuerdo de paz firmado entre el gobierno de Juan Manuel Santos y la antigua guerrilla de las Fuerzas Armadas Revolucionarias de Colombia (FARC), en noviembre de $2016,{ }^{7}$ es la posibilidad que ahora tienen

5 “Colombia: pelea en tribunales por el cadáver del "Mono Jojoy". Disponible en: <https:/www.bbc.com/mundo/noticias/2010/12/101221_colombia_farc_ mono_jojoy_entierro_vh>. Consultado el 10 de junio de 2020.

6 "Las heridas que revivieron con el homenaje a la tumba del Mono Jojoy". Disponible en: <https://www.semana.com/nacion/articulo/desentierran-al-mono-jojoy-farc-le-rinde-homenaje/541381>. Consultado el 10 de junio de 2020. ${ }^{7} \mathrm{El}$ "Acuerdo final para la terminación del conflicto y la construcción de una paz estable y duradera" incluyó seis puntos acordados luego de casi cinco años de negociaciones: Reforma Rural Integral; Participación Política; Fin del Con- 
miles de familias de buscar a sus seres queridos, combatientes de las FARC, dados por desaparecidos, muchos de ellos muertos en distintas circunstancias durante la guerra. Una posibilidad negada durante décadas, pues recuperar los cuerpos de sus familiares en los casos en que sabían que habían muerto y que habían sido trasladados en helicópteros - no sólo les suponía un riesgo para sus vidas, también, como en el caso de los familiares de Jorge Briceño, rechazos constantes en las instituciones, señalamientos de las comunidades y largos procesos judiciales. Las suyas fueron, durante décadas, búsquedas — duelos_ clandestinas. La antesala de esa oportunidad de preguntar abiertamente por sus seres queridos se dio en las sabanas del Yarí, un vasto territorio ubicado al sur oriente de Colombia en el que la insurgencia más antigua del continente americano tendría su décima, y última, conferencia guerrillera. "La décima", como se le conoció coloquialmente, se celebró en septiembre de 2016 y a ella no sólo llegaron cerca de doscientos combatientes delegados de todos los Frentes de las FARC para refrendar el Acuerdo de paz. También cientos de familiares que buscaban alguna noticia de su pariente vinculado a la guerrilla; de su familiar retenido por la guerrilla o de su familiar desaparecido por dicha guerrilla.

Si bien las antiguas FARC han sido responsables de retenciones, secuestros y desapariciones a lo largo del conflicto armado colombiano, ${ }^{8}$ por los que a la fecha sus miembros se encuentran

flicto; Solución al problema de las drogas ilícitas; Víctimas: Sistema Integral de Verdad, Justicia, Reparación y No Repetición; implementación, verificación y refrendación. La totalidad del Acuerdo está disponible en la página: <https:// www.cancilleria.gov.co/sites/default/files/Fotos2016/12.11_1.2016nuevoacuerdofinal.pdf>.

${ }^{8}$ Según los datos del "Observatorio del conflicto armado", del Centro Nacional de Memoria Histórica, en más de cincuenta años de guerra, las guerrillas en Colombia serían responsables de cerca de 10441 desapariciones; de más de veinte mil secuestros y de cerca de cuatro mil asesinatos selectivos. Las cifras del Observatorio sobre el conflicto colombiano están disponibles en la página web del Centro Nacional de Memoria Histórica: <http://centrodememoriahistorica. gov.co/observatorio/>. 
enfrentando procesos ante la Jurisdicción Especial para la Paz, el presente artículo centra la mirada en aquellos combatientes de esta insurgencia que han sido dados por desaparecidos y en la experiencia de las búsquedas emprendidas, no nada más por familiares sino por algunos de sus excompañeros de filas que, tras la firma del Acuerdo de paz, conformaron una Comisión para la búsqueda de las personas desaparecidas en Colombia durante la guerra. Ello me permite exponer cómo es que las vidas de los miles de combatientes de las FARC muertos durante las hostilidades no fueran consideradas como vidas vivibles y vidas merecedoras de duelos ${ }^{10}$ por parte de distintas entidades estatales y del grueso de la sociedad colombiana, y contribuyó a que las formas en las que familiares de combatientes tenían que hacer las búsquedas y los duelos fueran, en la mayoría de los casos, clandestinas, sin cuerpos y sin certezas. Dado que estas situaciones no tendrían cabida en la definición clásica de las personas desaparecidas, el presente artículo se apoya en el concepto de desaparecido social, definido como

una categoría que surge de contextos en los que los datos propios de la desaparición se hacen comunes, hasta masivos, y en los que los entornos afectados acuden a ella para calificar existencias que escapan de los conceptos heredados de vida, de humano, de existencia o incluso de muerte. Así, muertes en vida, muertes sociales, vidas sin registro caben en este giro. ${ }^{11}$

\footnotetext{
${ }^{9}$ Debido a que la categoría jurídica de desaparecido en Colombia no contemplaba, entre otros casos, aquellos de los combatientes caídos en combate, "A partir de los procesos de negociación en La Habana y del debate por la ampliación de los responsables, se consideró introducir la expresión personas dadas por desaparecidas, para reconocer las exigencias de los familiares de los combatientes caídos que también son objeto de búsqueda incesante por parte de sus seres queridos". Centro Nacional de Memoria Histórica, Hasta encontrarlos. El drama de la desaparición forzada en Colombia, p 19.

${ }^{10}$ Judith Butler, Vida precaria: el poder del duelo y la violencia.

${ }^{11}$ Gabriel Gatti, Ignacio Irazuzta y María Martínez, "Introducción. La desaparición forzada de personas: circulación transnacional y usos sociales de una categoría de los derechos humanos", p. 150.
} 
Ello, para abordar algunas prácticas que sucedían tras combates o bombardeos (los traslados de cuerpos en helicópteros, los entierros informales, la negación de la entrega de cuerpos a familiares, entre otras), como constitutivas de desaparición social bajo la razón de la ilegalidad. ${ }^{12}$ Este concepto también es útil para vincular aquí algunas experiencias de búsquedas y de reencuentros de excombatientes con sus familiares. Esto, teniendo en cuenta, por una parte, que tanto los casos de ingresos voluntarios al grupo armado, como aquellos de reclutamientos forzados, fueron a menudo denunciados ante entidades estatales como casos de desaparición. ${ }^{13}$ Por otra parte, que el ingreso al grupo armado y la ausencia de certezas sobre lo que había sucedido con quien militaba en la guerrilla, motivó la invisibilización social de muchos familiares. Así, me refiero aquí a combatientes dados por desaparecidos a aquellos $i$ ) combatientes desaparecidos en medio de las hostilidades de los que no se tiene certeza de su paradero; ii) combatientes cuyos cuerpos no han sido recuperados por sus familiares, aunque sepan que está muerto; iii) personas que ingresaron a las filas de las FARC, cuyos seres queridos duraron años sin tener certeza de su suerte, aunque posteriormente se hubieran podido reencontrar.

${ }^{12}$ Sobre la ilegalización de las vidas véase Ignacio Irazuzta, Silvia Maeso, Jaume Peris Blanes, "Políticas de aparición/desaparición”, pp. 155-168.

${ }^{13}$ En Colombia el delito de desaparición forzada se tipificó en la Ley 589 del año 2000 de la siguiente manera: "El particular que perteneciendo a un grupo armado al margen de la ley someta a otra persona a privación de su libertad cualquiera que sea la forma, seguida de su ocultamiento y de la negativa a reconocer dicha privación o de dar información sobre su paradero, sustrayéndola del amparo de la ley, incurrirá en prisión de veinticinco (25) a cuarenta (40) años, multa de quinientos (500) a dos mil (2 000) salarios mínimos legales vigentes y en interdicción de derechos y funciones públicas de cinco (5) a diez (10) años. A la misma pena quedará sometido, el servidor público, o el particular que actúe bajo la determinación o la aquiescencia de aquel, y realice la conducta descrita en el inciso anterior". <https://www.defensoria.gov.co/public/ Normograma\%202013_html/Normas/Ley_589_2000.pdf $\geq$. Consultado el 10 de junio de 2020 . 
Para su abordaje, el texto se divide en tres partes. La primera, toca algunos marcos desde los que se han realizado tanto los análisis como las búsquedas de excombatientes y la entrega de sus cuerpos a familiares: el de la guerra y el del postacuerdo, enfatizando en este último algunas experiencias de reencuentros y búsquedas a partir de la celebración de la "décima conferencia" y del traslado de guerrilleros y guerrilleras a las antiguas Zonas Veredales Transitorias de Normalización (ZVTN). ${ }^{14}$ La segunda parte aborda el imaginario social de las identidades de los excombatientes como sujetos negados ${ }^{15} \mathrm{y}$ el proceso de duelos y búsquedas clandestinas que algunos familiares han tenido que llevar, viviendo en la invisibilidad. ${ }^{16}$ La tercera parte, a manera de invitación, más que de incipiente conclusión, señala cómo la imposibilidad de visibilizar esas vidas, de darles nombres y reconocer sus historias, tiene implicaciones profundas en la construcción de comunidad en un país como Colombia, en un escenario de postacuerdo que sigue atravesado por el conflicto armado. Asimismo aboga por la necesidad de mayores estudios que permitan profundizar en la complejidad de las desapariciones sociales de guerrilleros y guerrilleras, así como de las experiencias de sus familiares, en Colombia.

${ }^{14}$ Las ZVTN fueron espacios ubicados en distintos lugares de la geografía colombiana a los que llegaron los excombatientes de FARC para facilitar el monitoreo del Cese Bilateral y Definitivo y de la Dejación de Armas, así como el inicio del proceso de reincorporación, dispuestos en el punto 3, "Fin del conflicto" del Acuerdo de paz. Actualmente, la mayoría de las ZVTN se transformaron en Espacios Territoriales de Capacitación y Reincorporación (ETCR), lugar donde cerca de tres mil excombatientes desarrollan sus procesos de reincorporación. Para más información sobre dicho proceso véase: Lorena Carrillo González, "La llegada es el punto de partida. Otra mirada al traslado de los integrantes de las FARC-EP a las Zonas Veredales Transitorias de Normalización y los Puntos Transitorios de Normalización”; Comité de Acompañamiento de la sociedad civil al Mecanismo de Monitoreo y Verificación del Cese al fuego y de hostilidades bilateral y definitivo, "El cese bilateral más allá del fuego".

${ }^{15}$ Gabriel Gatti, "Prolegómeno para un concepto científico de la desaparición”, en Gabriel Gatti (ed.), Desapariciones. Usos locales, circulaciones globales.

${ }^{16}$ Irazuzta, Maeso y Peris Blanes, "Políticas de aparición/desaparición", op. cit., p. 164

De los duelos clandestinos a las búsquedas de desaparecidos / 203 


\section{LOS MARCOS SOCIALES PARA LA COMPRENSIÓN Y LA BÚSQUEDA DE INSURGENTES EN COLOMBIA}

Después de todo, si alguien desaparece, y esa persona no es nadie, ¿entonces qué y dónde desaparece, $y$ cómo puede tener lugar el duelo?

Judith Butler

De la misma manera que los atentados del 11 de septiembre en Estados Unidos alentaron una visión binaria del "o se está con nosotros o se está con los terroristas", que llegó a generar sesgos en la perspectiva crítica de intelectuales contra la guerra, ${ }^{17}$ en Colombia la centralidad dicotómica victima-victimario en el análisis del conflicto armado ha limitado la posibilidad de producir análisis críticos que aporten a la comprensión de las causas del conflicto, y, sobre todo, a desarrollar análisis complejos de las guerrillas y de sus combatientes que superen discursos vergonzantes de guerreros vencidos o lugares de enunciación asépticos sobre su experiencia de lucha armada o sobre el sentido dado a la violencia política,

A menudo, sobre las personas ex combatientes pesa el sesgo de la deserción, de la desmovilización. Dicho sesgo alimenta, en cierta medida, las narrativas tradicionales y dicotómicas sobre la guerra, caracterizadas por omitir deliberadamente las subjetividades políticas de quienes han trasegado con un fusil parte de su vida. Estas narrativas llevan a ex combatientes, si no a un arrepentimiento explícito, por lo menos a omitir cualquier experiencia política (o positiva) de su paso por un movimiento armado. ${ }^{18}$

Así, la neutralización de la experiencia, o el tratamiento de ese pasado como algo que nunca tendría que haber ocurrido, se

${ }^{17}$ Butler, Vida precaria, op. cit., p. 26.

${ }^{18}$ Lorena Carrillo González. "La mujer de los 7 nombres y la narración de las experiencias de ex combatientes". 
vuelve casi que condición para la aceptación de ex combatientes por una parte importante de la sociedad; para una real reincorporación y para legitimar ante la opinión pública la búsqueda de aquellos que cayeron durante las hostilidades. Debido a la continuidad de la guerra y a las dificultades que supone el análisis historiográfico de un fenómeno aún presente, Alexander Betancourt en su artículo sobre la insurgencia en Colombia señala que,

La información relativa a la insurrección armada en Colombia está marcada por ciertas particularidades; en primera instancia, por el carácter permanente del conflicto armado. Esta situación supone que la producción bibliográfica que aborda el tema lo hace, prioritariamente, desde la coyuntura. Es por ello que, si bien la insurrección es un objeto de estudio obvio, como fenómeno político, social y económico, todavía está activo; por lo tanto, el análisis y las aproximaciones explicativas directas sobre este actor en la historia reciente colombiana, recaen en una producción que está vinculada a la inmediatez -las entrevistas y reportajes- o a los trabajos testimoniales producidos por ex miembros de los grupos armados y por los periodistas que elaboran crónicas y entrevistas. ${ }^{19}$

De modo que, entre otras cosas, en Colombia si bien ha existido una amplia producción académica sobre la guerra y las insurgencias, son pocos los estudios en los que se aborde lo acaecido con los cuerpos de aquellos que murieron en combates o bombardeos y desaparecieron, desde la perspectiva de la búsqueda y del sufrimiento de familiares de guerrilleros y guerrilleras. Abordar las búsquedas en un país polarizado en alto grado, implica que, como fenómeno activo, aun se considera a las y los insurgentes como enemigos, como el otro peligroso. Implica comprender el odio contrainsurgente como una construcción social que legitima su desaparición en la esfera pública y obliga a la invisibilidad en la esfera privada,

${ }^{19}$ Alexander Betancourt, "Insurgencia en Colombia, 1959-2012", p. 185.

De los duelos clandestinos a las búsquedas de desaparecidos / 205 
el odio puede aparecer en la guerra para formar una trinidad con la relación de enemistad y la violencia. De hecho, es una de las pasiones que se ha formado para animar o contribuir parcialmente a la movilización contrainsurgente. Ella ha intervenido en parte en acciones tales como el enrolamiento en las organizaciones paramilitares, la financiación de la campaña de exterminio, el silencio complaciente ante algunas atrocidades y la queja ante otras, los numerosos pequeńos actos de negligencia, la justificación de los agravios paramilitares, la propaganda, la identificación con los perpetradores y, finalmente, la violencia contrainsurgente. Ésta ha sido una pasión movilizadora consistente en un sentimiento de aversión tanto social como subjetiva hacia la insurgencia - y a lo que pueda guardar con ella alguna coincidencia en objetivos políticos-, a la cual se le desean males como el encarcelamiento o la persecución militar y criminal hasta el aniquilamiento, así ello comporte el sacrificio de algunas libertades negativas. Ese odio parte de la imaginación de la insurgencia y sus afines como causas de los males de la patria y desencadena un esfuerzo colectivo por inferir mal, por castigar y destruir. ${ }^{20}$

Así que, pese a la usual producción académica sobre excombatientes sobre quienes pesa el sesgo de la deserción, o de la reinserción a la vida civil; ${ }^{21}$ de trabajos sobre los principales ideólogos y comandantes de las FARC-EP;22 o a la cada vez más amplia circulación de textos sobre mujeres combatientes, ${ }^{23}$ la producción

${ }^{20}$ Liliana Franco Restrepo, Orden contrainsurgente y dominación, pp. 115-116.

${ }^{21}$ Véase, por ejemplo: León Valencia. Mis años de guerra.

${ }^{22}$ Véase por ejemplo los trabajos de Arturo Alape: La paz, la violencia: testigos de excepción; Las vidas de Pedro Antonio Marín, Manuel Marulanda Vélez, Tirofijo; Tirofijo: los sueños y las montañas. De Alfredo Molano, Trochas y fusiles. De Carlos Arango, Veinte años. De Marquetalia a la Uribe. En años recientes resaltan los trabajos sobre las FARC-EP de Carlos Medina Gallego. "FARC-EP y ELN. Una historia política comparada (1958-2006)” y de Miguel Ángel Beltrán. Las FARC-EP (1950-2015): Luchas de ira y esperanza.

${ }^{23}$ Véase, por ejemplo, entre otros, los trabajos de: Patricia Lara, Las mujeres en la guerra. De Luz María Londońo y Yoana Fernanda Nieto Valdivieso, Mujeres no 
académica sobre las guerrillas en Colombia también ha estado mediada por un fuerte debate político, en el que "invocando una pretendida neutralidad académica han propalado una serie de tesis canónicas sobre la guerrilla colombiana cuya premisa básica es la condena moral, tácita o explícita de la violencia política”, ${ }^{24}$ lo que ha imposibilitado mayores análisis de las vidas, de las historias y del sentido que aquellos que han hecho parte de movimientos armados le dieron a la violencia política que ejercieron, así,

junto con la experiencia de la violencia surge un marco para poder pensarla - un marco que funciona tanto para prevenir cierto tipo de preguntas y de análisis históricos, como para producir una justificación moral de la venganza-. Parece crucial prestarle atención a este marco, desde el momento en que él es el que decide, de manera forzosa, lo que puede escucharse, si una postura va a ser tomada como una explicación o como una absolución, si seremos capaces de percibir la diferencia y de aceptarla. ${ }^{25}$

Son, pues, aún más incipientes los estudios en los que se pueda puntualizar la temática de las búsquedas y de las desapariciones de (ex)combatientes. Por supuesto, si ese ha sido el escenario de los estudios y del imaginario colectivo sobre los insurgentes, los resultados en términos de búsqueda de combatientes desaparecidos no podrían ser distintos. Finalmente, ante el apremio de un registro de más de setenta mil víctimas civiles de desaparición forzada entre 1958 y 2018 en Colombia, ${ }^{26}$ varias atribuidas a las FARC, la

contadas. Proceso de desmovilización y retorno a la vida civil de mujeres excombatientes en Colombia. 1990-2003; y de María Victoria Uribe, Hilando fino: voces femeninas en la violencia.

${ }^{24}$ Beltrán, Las FARC-EP (1950-2015), op. cit., p. 27.

${ }^{25}$ Butler, Vida precaria, op. cit., pp. 27-28.

${ }^{26} \mathrm{El}$ "Observatorio del conflicto armado", del Centro Nacional de Memoria Histórica registra un total de 79245 víctimas civiles de desaparición forzada en dicho periodo de tiempo, alcanzado sus mayores picos entre los ańos de 1999 y 2007, cit. 
utilización de recursos públicos para la búsqueda de aquellos que cayeron durante las hostilidades, para darles nombre a esos cuerpos, no revestía ninguna prioridad. Esto es que,

cuando se aborda la desaparición quien la investiga está a veces atrapado por obligaciones que en no pocas ocasiones comprimen, si no cancelan, las posibilidades de profundización en la categoría que esconden sus trabajos. Esas obligaciones toman a veces las hechuras propias de la agenda moral de la "economía del humanitarismo" [...] que por moral o por institucionalizada propende hoy a llenarse de preceptos, protocolos, mandatos, $y$, lo que es peor, de prohibiciones: de qué se puede hablar y de qué no, y si se puede, cómo y cómo no hay que hacerlo. ${ }^{27}$

No solo se trata entonces de lo que se puede y de lo que no se puede hablar. Sino de a quién se podía y a quién no se podía buscar. La ilegalidad que reviste a aquellos insurgentes que decidieron alzarse en armas contra un Estado validó su negación, su desaparición social: estás personas no eran normativamente humanos. ${ }^{28}$ Estaban ya en un espacio de negación como ciudadanos.

\section{La Negociación, el Acuerdo y las búsquedas}

Cuando aún se encontraban en proceso de negociación, en octubre de 2015, Gobierno y FARC dieron a conocer desde La Habana el Comunicado Conjunto 062. En él, "con el fin de aliviar el sufrimiento de las familias de las personas dadas por desaparecidas y de esta manera contribuir a la satisfacción de sus derechos", ${ }^{29}$ las partes acordaron, además de la creación de la Unidad de Bús-

${ }^{27}$ Gatti, Martínez e Irazuzta. "Introducción”, op. cit., pp. 145-155.

${ }^{28}$ Butler, Vida precaria, op. cit.

${ }^{29}$ Véase Gobierno-FARC-EP, Comunicado conjunto 062. 
queda de Personas dadas por Desaparecidas en el contexto y en razón del conflicto armado (UBPD), ${ }^{30}$ que

el Gobierno Nacional acelerará por una parte la identificación y entrega digna de restos de víctimas y de quienes hayan muerto en desarrollo de operaciones de la Fuerza Pública inhumados como N.N. en cementerios ubicados en las zonas más afectadas por el conflicto, de acuerdo con las recomendaciones que haga el Instituto Nacional de Medicina Legal y Ciencias Forenses; y por otra parte la entrega digna de los restos identificados que no hayan sido aún entregados a sus familiares. Cuando sea necesario se solicitará el apoyo del CiCR para la entrega digna de los restos a los familiares de los miembros de las FARC-EP. Que las FARC-EP entregarán la información para la ubicación e identificación de los restos de víctimas de cuya ubicación tengan conocimiento, y contribuirá a la entrega digna de los mismos. ${ }^{31}$

La emisión del Comunicado Conjunto abrió la posibilidad de una búsqueda humanitaria, tanto para civiles como para miembros de grupos armados que hubieran desaparecido durante la conducción de las hostilidades. Para los (ex)combatientes de FARC, marcó también el origen del grupo de trabajo que a la fecha

30 "La Unidad de Búsqueda de Personas Dadas por Desaparecidas es un mecanismo extrajudicial y humanitario, autónomo e independiente dentro del Sistema Integral de Verdad, Justicia, Reparación y No Repetición (sIvjrnR). Fue convenida mediante el Acuerdo Final para la terminación del conflicto y la construcción de una paz estable y duradera, firmado por el Estado colombiano y las FARC-EP el 24 de noviembre de 2016, en respuesta a la solicitud de los familiares de las personas desaparecidas y las organizaciones civiles que participaron en los diálogos de paz en La Habana (Cuba). Tiene como objetivo dirigir, coordinar y contribuir a la implementación de las acciones humanitarias de búsqueda y localización de personas dadas por desaparecidas en el contexto y en razón del conflicto armado que se encuentren con vida y, en los casos de fallecimiento, cuando sea posible, la recuperación, identificación y entrega digna de cuerpos". Para más informaciónse puede consultar la página web de la entidad: <ubpdbusquedadesaparecidos.co/acerca-de-la-busqueda/>.

${ }^{31}$ Gobierno-FARC-EP, Comunicado conjunto 062, cit. 
conforma la Comisión de Búsqueda de Desaparecidos de FARC, que se encarga de contribuir con la búsqueda de personas desaparecidas. Para Mireya Andrade, excombatiente e integrante de dicha Comisión, tras la firma del Acuerdo de paz,

se hacía necesario buscar a los combatientes de ambos lados que desaparecieron, pero también a los desaparecidos integrantes de la población civil. Este Acuerdo que firmaba el fin de la confrontación armada entre el Gobierno Nacional y las FARC-EP, tiene un fondo eminentemente social por lo tanto sus soluciones deberían complacer a la sociedad y a las causas que la generaron, por eso las victimas debían ser el centro de preocupación y resarcirlas una condición.

Pero este proceso de creación de la Comisión de Búsqueda de personas desaparecidas nace de la angustiosa petición de los familiares de las victimas desaparecidas, contando con el respaldo de organizaciones nacionales e internacionales que nos compartieron las experiencias de otros países, y contando con la vocación humanista de las FARC y los delegados del Gobierno Nacional, eso hizo posible que concluyéramos acordando este paso en bien de los avances hacia la paz.

La situación de miles de familias, incluidas las de combatientes que han sufrido la desaparición de sus seres —o que al enterarse de su muerte en confrontación no pudieron reclamar sus cuerpos por la situación de seguridad reinante, por la amenaza o por la estigmatización - también porque durante los combates se dieron pérdidas de personas, que luego atribuyeron que fueron retenidas por FARC y esas familias sabían que su ser querido era del ejército y luego les informan que la guerrilla los retuvo, sin ser verdad. Aclarar esos sucesos y ayudar en ese proceso humanitario fue el compromiso.

Se inició el trabajo en lugares que, por su resonancia nacional o eventos, se convirtieron en emblemáticos, contando lo sucedido, mostrando los hechos junto con las comunidades. Luego del proceso de ubicación de las unidades guerrilleras en los PPT (Puntos de pre agrupamiento Temporal) luego a las zvTN (Zonas 
veredales transitorias de Normalización), el trabajo se centró bastante en las actividades realizadas por el camarada Pastor [Alape] y sus acompańantes. En 2017 se retoma el trabajo y en medio de las dificultades del proceso de reincorporación, se nombran los encargados a nivel nacional con quienes se define trabajar la creación de los equipos en territorio. ${ }^{32}$

La Comisión de Búsqueda de FARC fue creada en 2016, para viabilizar las medidas humanitarias acordadas en el Comunicado Conjunto 062. La conforman cerca de 112 excombatientes, que viven en distintas partes del territorio nacional y trabajan en la búsqueda de personas desaparecidas durante el conflicto, bajo la dirección de Jaime Alberto Parra Rodríguez, "Mauricio Jaramillo", exmiembro del Secretariado. En septiembre de 2017 esta Comisión entregó información de 33 cuerpos de civiles, excombatientes y militares, con su ubicación, al Comité Internacional de la Cruz Roja (CICR) y esta entidad se encargó de su exhumación. ${ }^{33}$ Asimismo, en agosto de 2019 dicha Comisión hizo entrega pública, a la Unidad de Búsqueda de Personas dadas por Desaparecidas, de 276 formatos que "contienen información para la búsqueda, localización e identificación de personas dadas por desaparecidas en el marco del conflicto armado. Las personas reportadas como desaparecidas según la información recibida corresponden a: el 64\% miembros de grupos armados al margen de la ley; el 28\% civiles, y el 1\% integrantes de Fuerza Pública”. ${ }^{34}$

${ }^{32}$ Entrevista realizada en el mes de junio de 2020 a Mireya Andrade, integrante de la Comisión de Búsqueda del partido FARC.

${ }^{33}$ Consultado el 9 de junio de 2020: "La Comisión de Farc que busca a los desaparecidos”. Disponible en: <https://www.elespectador.com/colombia2020/ justicia/desaparecidos/la-comision-de-farc-que-busca-los-desaparecidos-articulo-857744/>.

34 "UBPD recibe de FARC información para la búsqueda de personas desaparecidas". Disponible en: <https:/www.ubpdbusquedadesaparecidos.co/actualidad/ ubpd-recibe-de-farc-informacion-para-la-busqueda-de-personas-desaparecidas/>. Consultado el 9 de junio de 2020. 
Tal como lo señala Mireya, durante la guerra, miembros de las FARC también aportaban información al CICR para apoyar la búsqueda de desaparecidos:

Se daban actividades de búsqueda y de entrega, casi todas con intermediación del Cicr. Ellos se acercaban a los campamentos con sus fichas de búsqueda de información solicitada por las familias. Esta actividad era considerada importante, porque la búsqueda no solo se daba desde la población civil, sino también desde los combatientes. El trabajo de búsqueda era realizado por las personas autorizadas para entrevistarse con CICR. O, en ocasiones, mandos quienes entregaban la información y ayudaban a ubicar a las familias, y posteriormente las familias recogían los cuerpos. ${ }^{35}$

De la misma manera, de acuerdo con Fidel Pérez, excombatiente de las FARC que reside en uno de los ETCR al oriente del país, siempre que las condiciones lo permitieran,

Se trataba de informar a las familias sobre sus seres queridos, cuando en un combate no podíamos sacar a nuestros compañeros y los cogía el ejército se informaba a la familia: "vea en combates con el ejército, de tal batallón, de tal unidad, de tal brigada, cayó su hijo. Lo recogieron en helicóptero tenemos la información completa. Vaya y reclámelo”. Esas cosas siempre tratábamos de registrárselas a la familia, de informárselas. Como también en muchos casos no se pudo hacer nada.

Hay familias que hoy, después del proceso nos plantean, “mire qué sabe de mi hijo. Ya se acabó el proceso y no sé nada de él, nunca supe si está vivo o si está muerto, se acabó el proceso y no sabemos dónde está". Yo les he dicho, pues si a estas alturas no aparece es porque su hijo en medio de la guerra murió y no se le pudo informar a la familia.

Nosotros siempre, en lo posible, mientras existieran las circunstancias, hacíamos lo posible porque el cuerpo del com-

${ }^{35}$ Entrevista realizada en el mes de junio de 2020 a Mireya Andrade, integrante de la Comisión de Búsqueda del partido farc. 
batiente, del guerrillero, se les entregara a sus familias. Inclusive, el caso de mi compañera que fue muerta en combate, logramos rescatar el cuerpo y buscamos a la familia y se lo entregamos y le dimos recursos financieros para colaborarle con el entierro y toda esa vaina, se le explicó cómo fue y se le hizo un reconocimiento heroico a la hija porque fue una gran combatiente. Eso lo hacíamos si las circunstancias se daban. ${ }^{36}$

Como me lo reiteró Fidel, no siempre se podía hacer la entrega de los cuerpos a los familiares. Aquellos cuerpos que eran trasladados por el ejército eran enterrados principalmente, tal como lo indicó el Comunicado Conjunto 062, como N. N. —Nomen Nescio, Ningún Nombre- en los cementerios de las zonas más afectadas por el conflicto armado. De acuerdo con el Instituto Nacional de Medicina Legal y Ciencias Forenses de Colombia, podrían ser más de 200 mil el total de cuerpos no identificados enterrados en todos los cementerios del país. ${ }^{37}$ Pese a este panorama, durante el último año de la negociación, muchos familiares lograron reencontrarse con sus seres queridos. La historia de $\mathrm{Na}-$ talia, por ejemplo, a quien conocí realizando mi trabajo de campo en la región de El Pato, es muestra de ello. A sus 16 años se reencontró, a principios del 2016, con su mamá. Miembro activo por ese entonces de la columna Teófilo Forero de las FARC-EP, quien ingresó cuando Natalia era aún muy pequeña:

La dejó a ella y a su hermano con su padre, quien prefirió entregarlos para que otras mujeres los criaran. A sus 13 ańos Natalia conoció a su mamá. Me contaba, aún emocionada, cómo fue ese

${ }^{36}$ Entrevista realizada en el mes de junio de 2020 a Fidel Pérez, excombatiente de las FARC.

37 “Colombia al menos 200 mil cuerpos sin identificar”. Disponible en: <https:// www.lafm.com.co/colombia/al-menos-200-mil-cuerpos-sin-identificar-estarian-ocultos-en-fosas-comunes>. Consultado el 9 de junio de 2020. Es importante precisar que el cálculo de la entonces directora del Instituto de Medicina Legal no sólo incluye los cuerpos violentados en razón del conflicto armado.

De los duelos clandestinos a las búsquedas de desaparecidos / 213 
encuentro: "Estaba muy nerviosa, no sabía qué sentir, sabía que por fin iba a ver a mi mamá, pero no sabía qué podía pasar". La llevaron a un campamento en algún lugar de las montańas de la cordillera oriental donde se encontraba Nora, allí permanecieron juntas por algunos días. Las vecinas de la región cuentan que Nora nunca desamparó a Natalia y a su hermano, que siempre les enviaba dinero y les hacía saber que ella estaba pendiente de ellos. "Ella se fue porque se enamoró de un guerrillero", dicen algunas personas; "el marido la maltrataba mucho, ella se aburrió de eso y prefirió pedir ingreso" dicen otras. Enamorada o no, cansada del maltrato o no, la mamá de Natalia duró 16 años en las filas de las FARC. Natalia y su hermano volvieron a visitar a su mamá en un campamento en marzo de 2016 [...] estaba emocionada, su mamá le había dicho que pronto volverían a estar juntas porque la guerra iba a terminar. ${ }^{38}$

Otros familiares se acercaron a la décima conferencia, para convertir ese espacio de discusión en un escenario de esperanza para preguntar por la suerte de sus seres queridos. Algunos lograron reencontrarse:

Cuando mi mamá lo miró, le palpó toda la cara, lo tocó por todos lados. Quería asegurarse de que estaba bien y yo creo que no sentía que esto fuera real. Se quedó mirándolo. Él no sabía que veníamos. No lo creía cuando nos vio. Nosotros nos abrazamos, no cabíamos de la emoción y la alegría tan tremenda de vernos después de 15 años. Fuimos al concierto, la mamá se tomó sus cervezas y estuvimos juntos. Ya quedo contento de saber que no le pasó nada. Está enterito, gordito, con una salud completamente envidiable. Me veo más viejito yo que él, y eso que soy menor.

Se fue a los 17 ańos, puro peladito. Vivíamos en Puerto Rico y teníamos a los paramilitares encima. Entonces tocaba que, con

${ }^{38}$ Lorena Carrillo González, "Cotidianidades desarmadas, el reto invisible de las transiciones territoriales: la ventana abierta de la Zonas Veredales Transitorias de Normalización en el proceso de paz con las FARC-EP”, pp 463, 464. 
la guerrilla, con los paras o al Ejército. Él decidió con las Farc. Nosotros decidimos Bogotá. A él, de todas maneras, le gustaba esto. Siempre los miraba cuando nos compraban una gallina y nos compartían a todos la cena. Ya llegó un día en que nunca volvió a amanecer en la casa. Se fue con el Frente que estaba por los lados de Currillo.

Nosotros éramos muy unidos. Jugábamos micro, pero nunca como contrincantes, siempre los dos contra todos. Hasta que se fue y se acabó el micro para mí. Los primeros años fueron pura tristeza, sobre todo porque uno sin saber nada y los medios diciendo que mataron a tal guerrillero, que bombardearon tal Frente. No volvió a comunicarse que porque no tenía teléfono y que porque tuvo un tropiezo en el que perdió todos los números. Y nosotros pegados a la televisión esperando que no dijeran su nombre en los muertos por combate. Pero mi mamá siempre lo sintió y supo que estaba vivo.

Yo vi lo de la Conferencia por las noticias. Y agarré el mapa satelital y averigüé dónde iba a ser esto. Cuando venía me entró la curiosidad de cómo lo iba a encontrar; si flaco o gordo, si mocho o entero, si vivo o muerto. Hay gente que ha venido acá y de chiripazo se encuentra con amigos o familiares. Como nosotros. Miramos caras conocidas y nos decían que "yo en el año tal lo vi en tal”, y preguntamos, toda una investigación, hasta que nos lo trajeron. Yo sabía que era la última oportunidad entonces me vine en la moto desde Bogotá. Quería ver bien la seguridad del lugar porque usted sabe que aquí uno no sabe, y los medios hacen mucho miedo. Pero esto acá se siente muy bueno, muy tranquilo, entonces mandé a traer a mi mamá en flota.

Acá viven muy relajados, diferente a Bogotá. Eso sí mi hermano que se prepare, porque vienen de una selva así a meterse a una selva una terrible. Los guerrilleros están haciendo la paz, pero hay otros que no y eso los pone en riesgo. Esta selva es una hermosura, pero allá afuera hay una selva que no conocen y que se los va a querer tragar. ${ }^{39}$

${ }^{39}$ Natalia Otero, "Buscar a un familiar guerrillero en la Conferencia de las Farc. Testimonios".

De los duelos clandestinos a las búsquedas de desaparecidos / 215 
El espacio de "la décima" fue limitado. A ella asistieron delegados, no la totalidad de combatientes, fueron pocos días y la multitud de personas dificultó los reencuentros. Por eso, cuando inició el proceso de preagrupamiento de combatientes por Frentes en distintas partes del país, y el traslado a las distintas Zonas Veredales Transitorias de Normalización, entre finales del 2016 e inicios del 2017, se propició otro escenario. Diversas organizaciones sociales y Juntas de Acción Comunal acompanaron el monitoreo del Cese al Fuego y de la Dejación de Armas en todo el país. Se creó el Comité de Acompañamiento de la Sociedad Civil al Mecanismo de Monitoreo y Verificación, del que fui su secretaria técnica, espacio de trabajo que me permitió conocer estas experiencias y reflexionar sobre ellas. La acción del Comité no se limitó a la pedagogía sobre el contenido del Acuerdo y a explicar con detalle todo el proceso de dejación de armas. Las organizaciones también apoyaron algunos reencuentros de combatientes con sus familiares. Así, por ejemplo, miembros de la Corporación por la Defensa de los Derechos Humanos Caguán Vive, con asiento en el municipio de San Vicente del Caguán, al sur de Colombia, recuerdan cómo lograron reencontrar a dos excombatientes con sus familiares:

Justo en el marco de la décima conferencia, por esas épocas, logró llegar a la Corporación Caguán Vive una solicitud de uno de los combatientes que estaba en las zonas de preagrupamiento, pidiendo que si podíamos ayudar a un muchacho que llevaba 21 años sin saber de la familia. Nos hicieron llegar los nombres de los familiares y nosotros lo que hicimos fue aprovechar las redes sociales para hacer un barrido con esos apellidos. Después de escribirle a muchas personas, por allá nos contestaron de la ciudad de Neiva. Fue una cosa maravillosa, porque el primero que respondió a nuestros textos fue un hermano, nosotros le preguntamos si él conocía a fulano de tal. Él nos dijo sí, pero él ya está muerto. Yo le escribí "no, él está vivo. Y está ubicado en tal espacio veredal”. No, eso fue una cosa emocionante... la 
mamá... Ya se imaginará esa reacción, de la mamá, de esa familia. Después pudimos comunicarnos por teléfono, ¡esa familia gritaba de la emoción! el hermano me decía que la mamá estaba muy feliz, porque después de 21 años... pues claro, hacía mucho tiempo ya lo daban por muerto. Esa fue una de las cosas maravillosas que nos proporcionó mucha satisfacción. Luego también nos llegó un dato de otro muchacho que la familia no sabía nada de él hacía 18 años. Ahí hicimos una articulación con la Agencia para la Reincorporación de esa época, porque la familia estaba en Manizales. Casos de ese tipo se presentaron cualquier cantidad. ${ }^{40}$

Por su parte, Fidel me refirió la experiencia que tuvo en una de las Zonas Veredales en el departamento de Arauca, donde fue encargado de los reencuentros:

Mucha gente, llevaban... ipero años! que no sabían nada de la familia. Por múltiples razones: porque la familia se corrió del lugar donde estaban y nunca supieron nada; porque el único familiar que tenían en la vereda lo mataron y no supieron dónde quedó la otra familia. Yo dirigí cuadrar todos los encuentros de los familiares y pues los que tenían contacto les decíamos, "llámelos y dígales que vengan dentro de una semana", porque tocaba intercalarlos. Todos no se podían traer al mismo tiempo, inclusive creamos un campamento solo para atender a los civiles, entonces iba el guerrero a atender a su familia y demoraba, póngale cinco días, y después venía otra familia y así. A todos se les dio la oportunidad. Hubo compañeros que no encontraron su familia. Es que muchos de nosotros estábamos desconectados de nuestro relacionamiento con la familia, por las mismas circunstancias de la guerra. ${ }^{41}$

Si bien existieron muchos casos de reencuentros exitosos, que lograron terminar con la angustia de familiares y excombatientes

${ }^{40}$ Entrevista a miembro de la Corporación Caguán Vive, junio de 2020.

${ }^{41}$ Entrevista a Fidel Pérez, cit. 
por la certeza de haberlos encontrado con vida, son muchos más los casos en los que los familiares — muchos de ellos también excombatientes - siguen sin tener certeza del paradero de su ser querido. Varios de ellos emprendieron acciones para la búsqueda al finalizar la negociación y con la firma del Acuerdo. Denunciando la desaparición o acercándose a instituciones para lograr recuperar los cuerpos. Así, por ejemplo, los familiares de otro de los máximos comandantes de las FARC conocido como Raúl Reyes, muerto en un bombardeo en marzo del 2008 en Ecuador, iniciaron los trámites para recuperar sus restos sólo hasta el año 2017.42 Mireya me contó también sobre la búsqueda de su hermana, que pusieron en conocimiento de las autoridades apenas en el 2019:

ser familiar de un desaparecido es un tema complicado. En el caso de nuestra familia, mi madre supo que mi hermana se había ido a conseguir trabajo, pero unos amigos nos confirmaron que ella se fue para la guerrilla. Con el tiempo nos dicen que hubo un asalto del ejército a una comisión, en ella estaba mi hermana. Hacía parte del 8 Frente y esto se dio cerca de El Bordo. Se dijo que ella fue herida y capturada. A pesar de haber hecho la búsqueda en todos estos años, no ha habido respuesta. Mucha desinformación y comentarios de sitios donde se supone está el cuerpo, pero hasta ahora nada. Mi madre sigue en la espera de su regreso. Y nosotros buscando a quienes puedan conocer o tener más información. La denuncia se hizo ante INML [Instituto Nacional de Medicina Legal y Ciencias Forenses] y Fiscalía el año pasado. Porque mi madre no sabía o no se le había informado de los hechos. ${ }^{43}$

42 "Familiares de Raúl Reyes reclaman sus restos". Disponible en: <https://www. youtube.com/watch?v=UnOFVcDP2pY>. Consultado el 10 de junio de 2020.

${ }^{43}$ Entrevista a Mireya Andrade, cit. 
Si bien la negociación y la firma del Acuerdo de paz han permitido a muchos familiares de combatientes denunciar la desaparición ante las autoridades judiciales colombianas, sus búsquedas no han estado exentas de las burlas, los señalamientos y las intimidaciones.

III. VIDAS NEGADAS, DUELOS CLANDESTINOS

Este proceso del duelo, yo creo que es un duelo que comenzó desde que ellos se fueron, porque el solo impacto para mis papá fue desolador. Una vez ellos parten hacia las filas de las FARC, pues allí comienza el duelo, fueron sus hijos mayores, luego sus nietos (sobrinos para mí). Era un eterno duelo, un eterno morir.

Siempre esperando noticias, siempre con la esperanza de que todo saliera bien.

Emilse Muñoz V.

Dados de baja; muertos en combate; guerrilleros abatidos; terroristas muertos; bajas en las filas de las FARC. Así, una gran parte de la cobertura mediática informó durante décadas sobre los operativos en los que las fuerzas militares "neutralizaban" a miembros de las FARC. Salvo cuando se trataba de algún miembro de alto rango de dicha guerrilla, fueron escasas las veces en las que se informaban los nombres - mucho menos la trayectoria de vida- de las personas que habían muerto en los bombardeos o en los combates. De acuerdo con las cifras del Observatorio del Conflicto, la cantidad de combatientes de las distintas guerrillas muertos en diferentes acciones bélicas en Colombia alcanzaría las 23483 personas. ${ }^{44}$ Sin tener posibilidad de establecer con precisión cuántos

\footnotetext{
${ }^{44}$ Observatorio del Conflicto, cit.
}

De los duelos clandestinos a las búsquedas de desaparecidos / 219 
de esos combatientes pertenecían a las FARC, se calcula que esta insurgencia perdió por lo menos a la mitad de sus miembros en acciones armadas y en los procesos de desmovilización individual promovidos, principalmente, por los gobiernos de Álvaro Uribe Vélez entre 2002 y 2010. . $^{45}$

¿Quiénes eran esos miles de muertos? ¿Cómo llegaron a ser parte de las filas de las FARC? ¿Ingresaron por ideología, hambre, obligación? ¿Fueron todos objeto de reclutamientos forzados? Estas preguntas adquieren relevancia desde la lectura del desaparecido social, debido a que muchos familiares denunciaron el enrolamiento a las FARC de sus seres queridos como casos de desaparición forzada. Esto, de acuerdo con las entrevistas sostenidas, se realizaba como una forma de activar las búsquedas, sin que los familiares fueran relacionados con la guerrilla, pues existe la percepción de que existen más garantías de buscar a las personas civiles que a los combatientes:

Es muy difícil cuando se enfrenta uno a la situación de buscar a su familiar, porque a veces cree uno que no se abren las mismas puertas que se abren para las otras personas que no tuvieron nada que ver dentro del conflicto, y esa es una de las razones por las que hay tantos desaparecidos que no fueron reportados, porque a su familia no se le daba la atención por el hecho de que fuera un guerrillero la persona que estaba buscando. ${ }^{46}$

Por ello, es preciso recordar que el trabajo de Miguel Ángel Beltrán señala que los ingresos a esta guerrilla no fueron ni solo

${ }^{45}$ Para un análisis de las estrategias de guerra de las FARC véase, entre otros: Camilo Echandía Castilla, "Situación actual de las FARC: Un análisis de los cambios en las estrategias y la territorialidad (1990-2011)"; Mario Aguilera, "Las FarC: auge y quiebre de su modelo de guerra". Para un recuento de las cifras véase: “Tras 50 años de guerra, las Farc están débiles más no derrotadas". Disponible en: <https://www.elpais.com.co/judicial/tras-50-anos-de-guerra-las-farc-estandebiles-mas-no-derrotadas.html>.

${ }^{46}$ Entrevista a Emilia, cit. 
coerción, ni pura convicción. A través de diversos relatos de guerrilleros, muestra que las razones para hacer parte del grupo armado son de lo más diversas y, difícilmente, se podrían considerar como casos clásicos de desaparición forzada:

Las entrevistas efectuadas a guerrilleros de las FARC ponen a prueba dos explicaciones que suelen esgrimirse como motivaciones para ingresar a esta organización armada: por un lado, aquellas que insisten en que se trata de un proceso de reclutamiento forzado y que el individuo permanece allí por temor, miedo o amenaza; $y$, por otro, aquellas que aducen exclusivamente motivaciones ideológicas. Esto no quiere decir que dichas motivaciones estén ausentes, sin embargo, no son las fundamentales [...] De acuerdo con la investigación realizada las motivaciones que expresan los jóvenes para vincularse a las FARC son de la más diversa índole y en principio podemos clasificarlas en cinco grupos: injusticias económicas, agravios derivados de la represión por parte de las fuerzas del Estado, historias familiares, motivaciones ideológicas y emocionales. ${ }^{47}$

Lo anterior me permite señalar que se debe a que, muchos de los combatientes de las FARC, fueron señalados como desaparecidos por sus familiares, tienen como lugar de origen territorios ${ }^{48}$ en los que se ha configurado una expresión del necropoder, ${ }^{49}$ que las prácticas institucionales de desaparición social, como el traslado de cuerpos sin identificar a cementerios, eran normalizadas.

\footnotetext{
${ }^{47}$ Beltrán, Las FARC-EP (1950-2015), op. cit., p. 63.

${ }^{48}$ Los datos recopilados por el Observatorio del Conflicto indican que el 75.8\% de las acciones bélicas se concentraron entre 1958 y 2018 en 260 municipios de Colombia, cit. De acuerdo con la geografía del conflicto, el Acuerdo de paz priorizó 170 municipios mayormente afectados por la guerra para desarrollar los Planes de Desarrollo con Enfoque Territorial (PDET), medida de implementación y priorización de los contenidos de la Reforma Rural Integral contemplada en el punto 1 del Acuerdo.

${ }^{49}$ Definido por Achille Mbembe como la forma en la que la soberanía se entiende como el derecho de matar. Achille Mbembe, "Necropolitique".
} 
La concepción que instituciones del estado central colombiano - y, en especial, las fuerzas militares - ha tenido de estos territorios y de quienes allí habitan, ha estado mediada por una excepcionalidad que ha permitido validar la eliminación física de quienes allí viven. Tal excepcionalidad, desde la perspectiva de Agamben, ${ }^{50}$ es la base normativa moderna del derecho de matar y de definir quién merece vivir y quiénes — como en el caso de los combatientes de las FARC - debían morir en el anonimato, en la ilegalidad, sin registro de su existencia. En tal medida, la concepción de qué hacer con los cuerpos de esos muertos no revestía mayores consideraciones para las instituciones; se enterraban en cementerios como cuerpos no identificados, eran sujetos que estaban ya borrados y que sólo existían como amenaza, como peligro. Que en exclusiva contaban para demostrar los logros de las fuerzas militares.

Por el contrario, para Mireya, los cuerpos de aquellos guerrilleros que caían en combate debían ser escondidos y se debía evitar al máximo que fueran llevados por la fuerza pública:

lo hacíamos por varias razones: una de ellas por seguridad de la familia y por los contactos a dónde lo podían llevar, lo que esto significaba en términos de información. Había temor a la persecución para las comunidades que serían hostigadas; y porque con el tema de los falsos positivos, o la manera como estos eventos eran expuestos en los medios (como triunfos, como escarmiento) hacían ver que quedábamos pocos, desanimando. Ese era un mensaje que podía ser creído por quienes no estaban en las zonas donde ocurrían las operaciones. Estas exposiciones en los medios de comunicación golpeaban los sentimientos de todos. ${ }^{51}$

$\mathrm{Al}$ respecto, vale la pena señalar que, para aquellas partes en confrontación, tener el cuerpo era también una forma de se-

${ }^{50}$ Giorgio Agamben, Estado de excepción.

${ }^{51}$ Entrevista a Mireya Andrade, cit.

222 / Lorena Carrillo González 
guir ejerciendo poder sobre él, algo que también ocurre con los detenidos-desaparecidos:

Los desafíos específicos que enfrenta el concealment deben entonces ser recordados con insistencia: se busca así seguir ejerciendo un poder directo sobre los muertos. La lógica de la acción opuesta a las prácticas de expulsión o descalificación, que asimilan el cadáver del enemigo con un desecho- consiste en apropiarse el cuerpo del enemigo mediante el doble recurso simbólico consistente en cosificar al individuo (convirtiéndolo realmente en un objeto), y borrarlo como sujeto (negando la identidad de la persona). Esta apropiación del cuerpo del enemigo permite, de modo accesorio, que la oposición política quede privada del recurso simbólico que podrían representar esos muertos. Ni héroes, ni víctimas, ni mucho menos mártires. ${ }^{52}$

Sin embargo, el qué hacer con los cuerpos no era sólo un asunto de cuidar los resultados de la conducción de las hostilidades. Para los miembros de las FARC era también cuestión de poder hacer las honras a quienes eran sus compañeros, de hacer que su muerte importara. De poder informar sobre lo sucedido, cuando se podía, a sus familiares. En últimas no se trataba de una operación mecánica (incluso burocrática), de enterrar cuerpos, sino de darle significado a su vida, en medio de la guerra:

Cuando un/a compañera/o perdían la vida —y para no perder el cuerpo o que fuera tomado por el ejército, o la policía- se debían hacer las paradas militares en sitios poco frecuentados por civiles y los entierros, si se hacían en cementerios, pocas personas de la comunidad se enteraban... para no perder el cuerpo. La captura por parte de organismos del Estado de los cuerpos era considerada por nosotros como una gran pérdida del secreto de lo sucedido y para ellos un trofeo.

${ }^{52}$ Elizabeth Anstett, "Comparación no es razón: a propósito de la exportación de las nociones de Desaparición Forzada y Detenidos-Desaparecidos”.

De los duelos clandestinos a las búsquedas de desaparecidos / 223 
Cuando perdíamos a un compañero o compañera en medio de la confrontación por cualquiera que fuera la causa: enfrentamiento, accidente o muerte natural se le realizaban los respectivos honores, de acuerdo con la situación y el tiempo. Nos reuníamos, acompanábamos su cuerpo y, teniendo en cuenta el sitio en que estuviéramos, se le realizaban honores militares: calle de honor, acompañamiento en posición de guardia durante el tiempo [del] velorio. Respetando las características del lugar. Eso nos sucedió en varias oportunidades. En el caso de una chica que cayó de una lancha en el río y se ahogó, luego de recuperar el cuerpo, nos dirigimos a un pueblo de comunidades negras y no nos permitieron abrir la tumba hasta ya el momento del entierro. La gente le teme a la muerte.

En lo posible se les comunicaba a las familias de lo sucedido.

El cuerpo era, por lo general, dispuesto con su uniforme, si las circunstancias lo permitían, sino $[s i c]$ bien limpio en ropa civil. Si había forma se buscaba un ataúd, de otra forma se enterraba en sábanas y plástico. ${ }^{53}$

Si bien en muchos casos los miembros de las Farc dieron entierro de acuerdo con sus posibilidades a varios de sus compañeros caídos en combates, ésta tampoco fue la generalidad durante la guerra. ¿Qué sucedía con aquellos cuerpos que eran trasladados del lugar del combate? ¿Cómo lograba la familia saber lo que había sucedido con su familiar?

Emilse Muñoz V. perdió a seis miembros de su familia. Todos integrantes de las FARC. Para ella no es fácil hablar de estos temas. Con la voz entrecortada y el dolor imposible de expresar, me cuenta lo que ha implicado para ella y su familia recuperar los cuerpos de sus seis familiares, uno de ellos de un importante comandante de las FARC abatido en un operativo militar en marzo del 2011:

${ }^{53}$ Entrevista a Mireya Andrade, cit.

224 / Lorena Carrillo González 
Ha sido un proceso clandestino, totalmente clandestino, y por ello hemos tenido señalamientos, citaciones a las unidades del Сті [Cuerpo Técnico de Investigación de la Fiscalía], hemos sido asediados en nuestras viviendas. En algunos casos nos tocó ir a recoger los cuerpos después de unos meses de estar enterrados, algunos después de años. Fue bastante difícil lograr que la Fiscalía tuviera algún respeto por entregarnos los cuerpos... no. Por el contrario, fuimos objeto de escarnio, de desprecio. Hasta de burla por parte de las personas que nosotros teníamos que buscar en las fiscalías de las respectivas poblaciones, para poder recuperar los cuerpos con la información que los mismos compañeros de las Farc nos habían dicho de dónde habían quedado los cuerpos. Eso es terriblemente doloroso, pasar estos caminos del proceso legal, para luego recogerlos en nuestras manos, descompuestos; luego buscar cómo trasladarlos, poder sepultarlos inmediatamente o recoger los huesitos, y hacer todo el proceso doloroso y costoso para poder transportarlos hasta la ciudad donde vivimos y darles pues una sepultura digna. ${ }^{54}$

La búsqueda que Emilse y su familia emprendieron para lograr recuperar los cuerpos de sus seres queridos no sólo se enfrentó a distintas trabas burocráticas y a costosos procesos administrativos. El hecho de ser familiar de miembros de las FARC también tuvo implicaciones sensibles para su seguridad y la de su familia:

En los casos de los desaparecidos nosotros todavía tenemos tres personas desaparecidas, no hemos podido encontrar, identificar, hay suposiciones de donde están, peor no hay estudios que digan esos cuerpos son. Sumado a esto hay una cosa familiar supremamente dolorosa, todo esto ha sido un daño terrible, por ejemplo, mi mamá que es una anciana, ha tenido que soportar la vigilancia 24 horas de personas desconocidas en las afueras de su casa, se quedaban en una cafetería que había al frente. Por mi parte tuve que estar confinada también, porque tuve vigilancia

${ }^{54}$ Entrevista a Emilse Muñoz, junio de 2020.

De los duelos clandestinos a las búsquedas de desaparecidos / 225 
motorizada mucho tiempo. Durante unos enfrentamientos, que fueron bastante cruentos, antes de morir el penúltimo de mis hermanos en un ataque al Frente donde él estaba, fueron más o menos dos meses en los que estuve casi que confinada, porque cuando salía a buscar alimento o a buscar algo, me insultaban o me tiraban la moto encima. Me tocó prácticamente un mes y medio antes de terminar clases retirar a mis hijos de los colegios porque era imposible salir de la casa. Los insultos, las llamadas, las amenazas siempre fueron constantes. Todo esto nos ha tocado vivirlo solos, sin acompańamiento, buscando a nuestros seres queridos, tratando de hacer los procesos legales, buscando ayudas para poder recuperarlos y como le digo, aún nos queda algunos por recuperar. ${ }^{55}$

Gabriel Gatti, entre otros académicos, ha venido contribuyendo a la literatura sobre las desapariciones, con la construcción de un concepto científico que permita incluir los nuevos fenómenos que se retratan bajo el concepto clásico de la desaparición: desde el desaparecido originario, hasta las nuevas desapariciones. ${ }^{56}$ Ello, señala Gatti, porque situaciones como la de los migrantes trasnacionales, las exhumaciones de personas fusiladas durante la guerra civil en España - y, para los efectos de este texto, los combatientes de grupos armados al margen de la ley que cayeron en combate- entre otros, no pueden ser entendidas en toda su complejidad a partir de dicha categoría. Para Fidel Pérez, por ejemplo, sus compañeros caídos en combate no serían desaparecidos como tal, pues señala que "sabíamos a dónde estaban, no son desparecidos, porque sabemos que murieron en combate y que se los había llevado el ejército. No teníamos esa percepción como para darle el término, no lo he encontrado de esa forma" ${ }^{57} \mathrm{La}$ afirmación de Fidel es importante para preguntarse qué ha cambiado

\footnotetext{
${ }^{55} \mathrm{Idem}$.

${ }^{56}$ Gabriel Gatti (ed.), Desapariciones. Usos locales, circulaciones globales.

${ }^{57}$ Entrevista a Fidel Pérez, cit.
} 
en la concepción de la desaparición para los excombatientes de las FARC y para abordar desde diversas perspectivas la situación de los combatientes dados por desaparecidos, pues si bien, tal como lo expresa Fidel, sabian qué había pasado con tal o cual compañero, ésta no era la situación de familiares, quienes siguen sin saber qué pasó, y se acercan a los antiguos miembros de las FARC a preguntar dónde están, por motivación propia o para cumplirles, justo, a sus familiares. De acuerdo con Emilia,

Gracias al Acuerdo de Paz, la búsqueda de desaparecidos de todas las partes ha podido ser más amplia, cuando se desarrolla la actividad desde el sentimiento personal, cuando se está en la misma situación y tiene uno sus seres queridos desaparecidos... siente el mismo dolor, eso hace que se haya tomado más consciencia de que hay otros en mi misma situación, sintiendo lo que estoy sintiendo. Aunque muchas personas manifiestan que emprenden la búsqueda es sobre todo para cumplirles a los papás que son los que han estado haciendo la petición de buscarlos. No lo hacen por ellos mismos, sino para contribuirles a otros a mitigar un poco esa pena. ${ }^{58}$

Así, las diversas situaciones que rodean a los combatientes dados por desaparecidos, así como las búsquedas emprendidas por familiares y excompañeros, contribuyen a la comprensión de éstos ya no como desaparecidos originales, sino como casos de desapariciones sociales, presentes en regímenes liberales, donde lo señalado por Mbembe

sobre el concepto de Sujeto soberano-libre-autónomo y el trabajo político sobre la vida-muerte es interesante para repensar la figura del detenido desaparecido. Esto es, nos remite a considerar cómo la formación del individuo ciudadano, su condición de posibilidad de aparecer y conformar el espacio público liberal,

${ }^{58}$ Entrevista a Emilia, cit.

De los duelos clandestinos a las búsquedas de desaparecidos / 227 
se ha formado históricamente sobre procesos de violencia estructural económico-política, racializada y sexualizada [...] Tanto las formas de ese poder como sus modos de producción de la desaparición serían, en este caso, mucho más difusas, dispersas y descentralizadas. Más que con formas clásicas de violencia ejercidas sobre el individuo-soberano construido como enemigo político, la desaparición social se relaciona con lógicas de (in)visibilización y exclusión social radical, que expulsa a buena parte de la población de las formas normalizadas de la vida en comunidad. Por ello, podría apuntarse que el objeto de esta desaparición, más que individuos-ciudadanos concretos, lo constituirían grupos complejos de población sacados fuera de los mecanismos de aparición clásicos de un Estado -migrantes, refugiados y desplazados. Es por ello que, en buena medida, el hábitat del desaparecido social es el de las "tendencias subterráneas" que operan como fuerzas de "expulsión" [...] que podrían ser comprendidas como los nuevos dispositivos de desaparición..$^{59}$

Por ello, señalo que los desaparecidos sociales no sólo serían los combatientes de las FARC a los que me he referido a lo largo del texto. De acuerdo con la propuesta de análisis de los tipos de desaparecidos que se presentan en regímenes dictatoriales y en regímenes liberales, retomada por Irazuzta, Maeso y Peris, ${ }^{60}$ esta categoría bien podría extenderse a una buena parte de familiares de guerrilleros y guerrilleras, quienes han tenido que invisibilizarse, mentir sobre sus vidas, sus dolores, sus duelos, y que se han convertido en individuos borrados de la comunidad política, que deben vivir en la invisibilidad para ser. ${ }^{61} \mathrm{Al}$ respecto señala Emilse:

Los duelos se hicieron siempre en silencio. Esas son las muertes y los entierros más dolorosos que puede haber: sepultar a nuestra

\footnotetext{
${ }^{59}$ Irazuzta, Maeso y Peris Blanes, "Políticas de aparición/desaparición”, op. cit., pp. 166-167.

${ }^{60}$ Idem.

${ }^{61}$ Ibidem, p.164.
} 
gente sin tenerla; solamente sabiendo por noticias confirmadas que habían caído en combate, que habían sido asesinados. Y llorar nosotros solos, mucha gente preguntándonos "qué le pasa o qué le pasó a su mamá que se puso tan mal”... y tener que decir cualquier cosa. Porque a nosotros nos tocó llorar seis veces, ¡hacer el duelo seis veces! sin poder hacerlo realmente, sin que nadie lo supiera. En esto se convirtió la vida cotidiana de nosotros, por una causa, por una patria, por una vida digna por nuestros compatriotas más vulnerados. Tanto es el duelo que aún no lo hemos podido completar, aún tenemos personas que no hemos podido darle una sepultura digna, mi mamá ya tiene 90 años y ella aún guarda la esperanza de poder vivir ese momento antes de irse.

Yo creo que a mis familiares no los negamos... no, no. Todos sabíamos qué familia éramos, cuántos éramos, pero siempre nos tocó decir cualquier otra cosa de sus profesiones y de sus familias, porque pues muchas personas de nuestra misma familia $-\mathrm{o}$ de nuestro entorno- conocían de ellos, pero nunca más los volvieron a ver, entonces esperaban que tuvieran esposas, hijos. Lo normal, lo cotidiano. Muchas veces nos tocó mentir o salirnos del tema, nos tocaba hacernos invisibles.

Pero, ojalá hubiéramos podido ser más invisibles durante todo el tiempo que tuvimos el asedio, las capturas, la persecución... y tantas veces desplazados de nuestra casa, de nuestro barrio, de nuestro pueblo, ya no sé ni cuántas veces tuvimos que andar por distintos lugares, nosotros y nuestra familia. De un lugar a otro. Ojalá hubiéramos podido ser totalmente invisibles, pero para la Fiscalía jamás lo fuimos. Siempre fuimos objetivo claro y siempre tuvieron toda la disposición y el tiempo para hostigarnos; eso sí para jamás prestar atención a lo que nosotros estábamos denunciando. Cuando ya pudimos denunciar, y perdimos el miedo, igual eso quedó en nada, eso fue después de los Acuerdos de La Habana. Aun así, ninguna de las denuncias de lo que perdimos, del asedio, tiene ningún valor para ellos, no ha habido ninguna resolución. ${ }^{62}$

${ }^{62}$ Entrevista a Emilse Muñoz, cit.

De los duelos clandestinos a las búsquedas de desaparecidos / 229 
Una muestra más del trato administrativo diferenciado que reciben familiares de los guerrilleros, de su invisibilización, es que la Ley de Víctimas y de Restitución de Tierras, Ley 1448 de 2011, mediante la cual "se dictan medidas de atención, asistencia y reparación integral a las víctimas del conflicto armado interno y se dictan otras disposiciones", señala en su artículo tercero que

para los efectos de la presente ley, el o la cónyuge, compañero o compañera permanente, o los parientes de los miembros de grupos armados organizados al margen de la ley serán considerados como víctimas directas por el daño sufrido en sus derechos en los términos del presente artículo, pero no como víctimas indirectas por el daño sufrido por los miembros de dichos grupos. ${ }^{63}$

Ello implica que, en términos de lograr reconocimiento de derechos como víctimas del conflicto, para su asistencia y reparación, personas como Emilse son rechazadas. La situación de Emilse y su familia bien podría asimilarse a la que han tenido que vivir miles más y que aun por miedo no han podido hablar o no tienen los medios suficientes para activar las búsquedas.

IV. Hacer ese dolor EQuivalente: ¿ES POSIBLE?

Antígona, cuando arriesga la vida al enterrar a su hermano en contra del edicto de Creonte, es un buen ejemplo del riesgo político que conlleva desafiar la proscripción del duelo público en tiempos en los que recrudece el poder soberano y la unidad nacional se vuelve hegemónica. ¿Contra qué límites culturales luchamos cuando tratamos de enterarnos de las pérdidas que se nos exige no recordar, cuando in-

${ }^{63}$ Ley de Víctimas y de Restitución de Tierras. Disponible en: <https://www.unidadvictimas.gov.co/sites/default/files/documentosbiblioteca/ley-1448-de-2011. pdfs. 
tentamos nombrar y traer así bajo la rúbrica de lo "humano" a todos aquellos que murieron a causa de los Estados Unidos y de sus aliados?

Judith Butler

¿Por qué escribir sobre los duelos de los familiares de combatientes?, ¿sobre sus búsquedas? ¿Acaso en un país atravesado, construido, por las violencias, con más de 200000 muertos y miles de civiles desaparecidos, con el asesinato casi diario de líderes sociales y de los, ahora, excombatientes, no es suficiente como para dedicarle esfuerzos a esas vidas catalogadas como vidas no merecidas? ¿Justo en tiempos en los que una pandemia deja miles de muertes a diario? Pretendiendo dar algunas respuestas sólo puedo señalar que este artículo es apenas un intento por apalabrar y pensar sobre aquello que se nos tenía prohibido pensar públicamente. En tal medida, esto, más que una conclusión, es una invitación a que podamos desafiar las lecturas tradicionales —a menudo marcadas por preceptos morales - sobre los estudios de las desapariciones en Colombia para abordar su enorme complejidad, sobre todo para aquellas familias que han tenido que vivir en la clandestinidad sus pérdidas y sus dolores. Así, propuse abordar las situaciones asociadas con los combatientes caídos en combate o dados por desaparecidos, no desde un abordaje clásico del desaparecido forzado, sino desde la desaparición social, que me permite extender la comprensión de la problemática de la búsqueda, no nada más a partir de la ausencia del guerrillero, sino desde la invisibilidad a la que han tenido que acudir sus familiares.

A lo largo del presente texto expuse las circunstancias que han rondando las búsquedas de (ex)combatientes de las FARC en Colombia, algunas de ellas en medio de la guerra, otras impulsadas por la negociación y la firma del Acuerdo de paz. Incluí las voces de tres mujeres y de un hombre que han tenido que enfrentarse a la búsqueda desde distintos lugares: Mireya, desde su trabajo en la Comisión de búsqueda de FARC; Emilia, que siendo excomba- 
tiente tiene familiares desaparecidos, se refirió a lo difícil que era para ellos afrontarse a los señalamientos de quienes creían que por ser guerrilleros o guerrilleras no tenían sentimientos y la muerte "no les dolía". Aquí señalo que es también este lugar el que les ha permitido hacerse más conscientes de los dolores y de lo que implica vivir con la ausencia de la certeza de lo que pasó con sus seres queridos. Fidel relató, con cierto pragmatismo, cómo hicieron "lo que pudieron" con sus muertos y con los reencuentros. Emilse, por su parte, compartió sus dolores, al no haber podido hacer el duelo de sus seis (¡seis!) familiares muertos en distintas circunstancias en medio de la guerra.

¿Qué pueden enseñarnos estas experiencias sobre el tipo de sociedad que tenemos en Colombia? ¿Por qué la persecución hacia familiares de guerrilleros y la prohibición para que pudieran expresar públicamente su dolor? ¿Por qué la imposibilidad de considerar ese dolor, por la pérdida — la de un hermano, una hermana, un hijo, una hija, un padre, una madre- como un dolor equivalente al de mis pérdidas?

La crisis desatada en el mundo a raíz del covid-19 hizo pública la reflexión sobre esos miles de muertos que fueron enterrados sin funeral, sin familia, sin ritual y que nos acostumbramos ver a diario en las redes sociales o en la televisión; cada día con un poco menos de asombro. Al respecto Marcela Turati, periodista mexicana, escribía en el New York Times la columna "Por el derecho al buen morir". En ella reflexionó sobre la importancia de los abrazos, de las despedidas:

\footnotetext{
"Así como declaramos que los vivos están vivos con el bautizo, que los amantes están enamorados con las nupcias, los funerales son la forma en la que cerramos la brecha entre la muerte que sucede y la muerte que importa. Es la manera en la que les damos significado a nuestras pequeñas historias memorables", escribe en El enterrador Thomas Lynch, quien además de poeta y ensayista tiene como oficio familiar el de agente funerario.
} 
Si velar a los muertos es importante para tener una oportunidad de decir adiós — plantea Lynch en su libro—, el ataúd supone que el cuerpo le importa a alguien. ${ }^{64}$

La columna de Turati me permite incluir aquí, como conclusión, la reflexión sobre lo que significa el buen morir, la buena muerte. Y, por ende, sobre lo que es gestionar la mala muerte o la muerte merecida, como se ha venido entendiendo la muerte de los guerrilleros. En su estudio, Liliana Franco advierte que la noción de seguridad y la administración de los miedos han sido motivaciones neurálgicas y articuladoras de un orden contrainsurgente. ${ }^{65}$ ¿Por qué solidarizarme con las familias de quienes han amenazado mi seguridad, la de mi comunidad? Hacer conciencia pública de esas pérdidas, hacer equivalente el dolor de familiares de aquellos sujetos que han representado para muchos el peligro, el miedo, durante tantas décadas en Colombia, es, bajo la lógica del orden contrainsurgente construido, imposible en la práctica, pues aquellas

Son vidas para las que no cabe ningún duelo porque ya estaban perdidas para siempre o porque más bien nunca "fueron", y deben ser eliminadas desde el momento en que parecen vivir obstinadamente en ese estado moribundo. La violencia se renueva frente al carácter aparentemente inagotable de su objeto. La desrealización del "Otro" quiere decir que no está ni vivo ni muerto, sino en una interminable condición de espectro. La paranoia infinita que imagina la guerra contra el terrorismo como una guerra sin fin se justifica incesantemente en relación con la infinitud espectral de su enemigo. ${ }^{66}$

\footnotetext{
${ }^{64}$ Marcela Turati, "Por el derecho al buen morir".

${ }^{65}$ Franco Restrepo, Orden contrainsurgente, op. cit.

${ }^{66}$ Butler, Vida precaria, op. cit., p. 60.
} 
La búsqueda de combatientes dados por desaparecidos se enfrenta en Colombia con, al menos, dos situaciones: la primera es su incipiente legitimación, en un país en el que un orden contrainsurgente ha sido parte de la constitución del orden social y ha moldeado el imaginario público sobre quiénes han sido señalados de terroristas, de enemigos. La segunda es la continuidad del conflicto armado. Tanto Mireya como Emilia señalaron que la búsqueda se hace más difícil porque el contexto actual, en el que se han incrementado las acciones armadas y la presencia de distintos grupos irregulares en los territorios, impide tanto el acercamiento a lugares donde podrían ubicarse cuerpos de combatientes, como posibilitar diálogos con quienes podrían tener información sobre las circunstancias en que los combatientes murieron o fueron dados como desaparecidos, por temor a ser señalados.

Así, la firma del Acuerdo de paz —y su problemática implementación — no nos deja únicamente la tarea del reconocimiento de los excombatientes en escenarios civiles como seres humanos, sujetos de derechos. También nos obliga a ser conscientes de las pérdidas que la guerra nos ha ocasionado, a comprender y valorar lo que esas pérdidas pueden significar para elaborar duelos colectivos, para comprender los impactos de las muertes por fuera de la dicotomía victima-victimario, para construir comunidad. Por supuesto, no me refiero aquí sólo a las pérdidas de víctimas civiles, a la vida de cientos de líderes sociales asesinados en los últimos tres años. También me refiero a la pérdida de hombres y mujeres marginados socialmente, excluidos políticamente, cuyas vidas nunca existieron en el espacio público, más que para confirmarlas como muertas. 医 


\section{BibliografíA}

"Acuerdo final para la terminación del conflicto y la construcción de una paz estable y duradera”. Recuperado de: <https:/www.cancilleria.gov. co/sites/default/files/Fotos2016/12.11_1.2016nuevoacuerdofinal.pdf>. Agamben, Giorgio. Estado de excepción, Buenos Aires, Adriana Hidalgo editora, 2005.

Aguilera, Mario. "Las farc: auge y quiebre de su modelo de guerra”, Análisis Político, vol. 26, núm. 77, 2013, pp. 85-111.

Alape, Arturo. La paz, la violencia: testigos de excepción, Bogotá, Planeta, 1985.

- Las vidas de Pedro Antonio Marín, Manuel Marulanda Vélez, Tirofijo, Bogotá, Planeta, 1989.

- Tirofijo: los sueños y las montañas. Bogotá, Planeta, 1994.

Anstett, Élizabeth. "Comparación no es razón: a propósito de la exportación de las nociones de Desaparición Forzada y Detenidos-Desaparecidos”, en Gabriel Gatti (ed.), Desapariciones. Usos locales, circulaciones globales, Bogotá, Siglo del Hombre Editores/ Universidad de Los Andes, 2017.

Arango, Carlos. FARC: Veinte años. De Marquetalia a la Uribe, Bogotá, Aurora, 2016.

Beltrán, Miguel Ángel. Las FARC-EP (1950-2015): Luchas de ira y esperanza, Bogotá, Ediciones Desde Abajo, 2015.

Betancourt, Alexander. "Insurgencia en Colombia, 1959-2012”, en Verónica Oikión Solano, Eduardo Rey Tristán y Martín López Ávalos (eds.), El Estudio de las luchas revolucionarias en América Latina (1959-1996): Estado de la Cuestión, Zamora (Mich.), El Colegio de Michoacán, y Santiago de Compostela, Universidad de Santiago de Compostela, 2014, pp. 185-208.

Butler, Judith. Vida precaria. El poder del duelo y la violencia, Buenos Aires, Paidós, 2006.

Carrillo González, Lorena. "Cotidianidades desarmadas, el reto invisible de las transiciones territoriales: la ventana abierta de la Zonas Veredales Transitorias de Normalización en el proceso de paz con las FARC-EP”, El Ágora USB, vol. 17, núm. 2, 2017, pp. 462-471.

- "La llegada es el punto de partida. Otra mirada al traslado de los integrantes de las FARC-EP a las Zonas Veredales Transitorias de Normalización y los Puntos Transitorios de Normalización”, Revista Cien días vistos por CINEP, núm. 90, 2017, pp. 13-17.

De los duelos clandestinos a las búsquedas de desaparecidos / 235 
- "La mujer de los 7 nombres y la narración de las experiencias de ex combatientes". Recuperado de: <https://lasiniestra.com/la-mujerde-los-7-nombres-y-la-narracion-de-las-experiencias-de-ex-combatientes/>.

Centro Nacional de Memoria Histórica. “¡Basta ya! Colombia: memorias de guerra y dignidad”. Recuperado de: <http://www.centrodememoriahistorica.gov.co/informes/informes-por-temas $>$.

- Hasta encontrarlos. El drama de la desaparición forzada en Colombia. 2016, Bogotá, cNMH.

- "Observatorio del conflicto armado". Recuperado de: <http:// centrodememoriahistorica.gov.co/observatorio/>.

Comité de Acompańamiento de la sociedad civil al Mecanismo de Monitoreo y Verificación del Cese al fuego y de hostilidades bilateral y definitivo. "El cese bilateral más allá del fuego", Bogotá, Cinep/ppp, 2017. Recuperado de: <https://www.cinep.org.co/publicaciones/PDFS/20170701. Informe_preliminar_MMV.pdf>.

Declaración conjunta Gobierno-FARC-EP (2015). Comunicado conjunto 062. Recuperado de: <http://www.centrodememoriahistorica.gov.co/ descargas/dialogos-paz-2015/comunicado-62-negociaciones-paz-2015. pdf>.

Echandía Castilla, Camilo. "Situación actual de las farc: Un análisis de los cambios en las estrategias y la territorialidad (1990-2011)". Series de Informes, núm. 13, Bogotá, Fundación Ideas para la Paz, 2011.

Franco Restrepo, Liliana. Orden contrainsurgente y dominación, Bogotá, Siglo del Hombre Editores, Instituto Popular de Capacitación, 2009.

Gatti, Gabriel. "Prolegómeno para un concepto científico de la desaparición”, en Gabriel Gatti (ed.), Desapariciones. Usos locales, circulaciones globales, Bogotá, Siglo del Hombre Editores/Universidad de Los Andes, 2017, pp. 7-19.

— Ignacio Irazuzta y María Martínez. "Introducción. La desaparición forzada de personas: circulación transnacional y usos sociales de una categoría de los derechos humanos", Oñati Socio-legal Series, vol. 9, núm. 2, 2019, pp. 145-154.

Gatti, Gabriel (ed.). Desapariciones. Usos locales, circulaciones globales, Bogotá, Siglo del Hombre Editores/Universidad de Los Andes, 2017.

Irazuzta, Ignacio, Silvia Maeso y Jaume Peris Blanes. "Políticas de aparición/ desaparición”, Ońati Socio-legal Series, vol. 9, núm. 2, 2019, pp. 155168. 
Kalyvas, Stathis. La lógica de la violencia en la guerra civil, Madrid, Akal, 2010.

Lara, Patricia. Las mujeres en la guerra, Bogotá, Planeta, 2000.

Londońo, Luz María y Yoana Fernanda Nieto Valdivieso. Mujeres no contadas. Proceso de desmovilización y retorno a la vida civil de mujeres excombatientes en Colombia. 1990-2003, Medellín, La Carreta editores, 2006.

Mbembe, Achille. "Necropolitique", 2003. Recuperado de: <http://www. cairn.info/article_p.php?ID_ARTICLE=RAI_021_0029\#pa1>.

Medina Gallego, Carlos. "FARC-EP Y eln. Una historia política comparada (1958-2006)”, tesis doctoral, Bogotá, Universidad Nacional de Colombia, 2010.

Molano, Alfredo. Trochas y fusiles, Bogotá, El Áncora Editores, 2007.

Otero, Natalia. "Buscar a un familiar guerrillero en la Conferencia de las Farc. Testimonios". Recuperado de: <https://pacifista.tv/notas/buscar-a-un-familiar-guerrillero-en-la-conferencia-de-las-farc-testimonios/>.

Turati, Marcela. "Por el derecho al buen morir. Recuperado de: <https:// www.nytimes.com/es/2020/05/05/espanol/opinion/muertes-coronavirus.html?fbclid=IwAR2DvGuoQmGztmQ_GSQco7XqiHINmFRyGi8N1qZ-ZMRdw6RC0o5ulBAfv_M>.

Uribe, María Victoria. Hilando fino: voces femeninas en la violencia, Bogotá, Editorial Universidad del Rosario, 2015.

Valencia, León. Mis años de guerra, Bogotá, Aguilar, 2014. 